\title{
Implementasi Sistem Manajemen Mutu ISO 9001: 2015 pada Program Studi Teknik Kimia di Akademi Minyak dan Gas Balongan Menggunakan Metode Interpretative Structural Modeling (ISM)
}

\author{
Suci Amaliah ${ }^{(1, a) *}$, Maya Dewi Dyah Maharani ${ }^{(1)}$ dan Tatan Sukwika ${ }^{(1)}$ \\ (1) Program Studi Magister Manajemen, Keselamatan Kesehatan Kerja Dan Lingkungan, \\ Universitas Sahid, Jakarta, Indonesia \\ Email : ${ }^{\left(a^{*}\right)}$ suci.a1993@gmail.com
}

Diterima (6 April 2021), Direvisi (22 Juni 2021)

\begin{abstract}
This research was aimed at developing a quality management implementation plan strategy based on ISO 9001: 2015 using the Interpretative Structural Modeling (ISM) method in the Chemical Engineering Department of Balongan Oil and Gas Academy. This research used a descriptive qualitative method. The results of research using the ISM method showed that in the elements of need there were key requirements needed in the strategy for the preparation of the implementation of QMS ISO 9001: 2015 in the Chemical Engineering Department of Balongan Oil and Gas Academy, namely the leadership sub-element and in the constraint elements there were key constraints on the implementation of the ISO 9001 QMS: 2015 at the Chemical Engineering Department of Balongan Oil and Gas Academy, namely the insufficiency of the role of top management to ensure that the quality management system had achieved the expected results and institutional management had not yet determined a change plan for the quality management system.
\end{abstract}

Keywords: Implementation, Quality Management System, ISO 9001:2015, Interpretative Structural Modeling.

Abstrak. Penelitian ini bertujuan untuk mengembangkan strategi rencana impelementasi manajemen mutu berdasarkan ISO 9001: 2015 menggunakan metode Interpretative Structural Modeling (ISM) pada Program Studi Teknik Kimia Akademi Minyak dan Gas Balongan. Metode penelitian ini menggunakan metode deksiptif kualitatif. Hasil penelitian dengan menggunakan metode ISM menunjukan bahwa dalam elemen kebutuhan terdapat kunci persyaratan yang dibutuhkan dalam strategi rencana persiapan impelementasi SMM ISO 9001:2015 di Program Studi Teknik Kimia Akamigas Balongan yaitu sub elemen kepemimpinan dan dalam elemen kendala terdapat kunci kendala pada implementasi SMM ISO 9001:2015 di Program Studi Teknik Kimia Akamigas Balongan yaitu kurangnya peran manajemen puncak untuk memastikan bahwa sistem manajemem mutu telah mencapai hasil yang diinginkan dan manajemen institusi belum menentukan rencana perubahan untuk sistem manajemen mutu.

Kata kunci: Implementasi, Sistem Manajemen Mutu, ISO 9001:2015, Interpretative Structural Modeling.

\section{PENDAHULUAN}

Pada masa ini di Indonesia ukuran keberhasilan dan mutu pendidikan tinggi diawasi dan ditetapkan oleh banyak pihak.
Menyadari hal tersebut, pemerintah berusaha meningkatkan mutu pendidikan tinggi agar menjadikan jasa pendidikan tinggi menjadi unggul dan mencetak lulusan dengan mutu yang baik. Pemerintah 
Suci Amaliah: Implementasi Sistem Manajemen Mutu ISO 9001: 2015 pada Program Studi Teknik Kimia di Akademi Minyak dan Gas Balongan Menggunakan Metode Interpretative Structural Modeling (ISM) Jurnal Migasian, e-issn: 2615-6695 / p-issn: 2580-5258

melalui sistem Akreditasi Perguruan Tinggi dan Pangkalan Data Pendidikan Tinggi (PD-Dikti) terus mengawasi peningkatan perguruan tinggi dan memberikan status peningktan sistem manajemen mutu agar dapat menjamin kualitas pendidikan bagi masyarakat, lembaga lain seperti ISO 9001:2015 merupakan salah satu upaya untuk meningkatkan sistem manajemen mutu pendidikan tinggi.

Implementasi sistem manajemen mutu bertujuan untuk meningkatkan mutu dan kepuasan pelanggan baik internal maupun eksternal dari sebuah organisasi ${ }^{[1]}$. ISO 9001:2015 adalah standar mutu internasional untuk sistem manajemen mutu. Sistem ini membantu organisasi untuk mengalola mutu barang dan jasa (goods and services) untuk memenuhi kebutuhan pelanggan. Apa bila sistem ini diterapkan dengan efektif akan meningkatkan efesiensi, efektifitas, dan produktifitas organisasi [2].

Akademi Minyak dan Gas (AKAMIGAS) Balongan merupakan salah perguruan tinggi swata, seluruh program studinya telah terakreditasi olah Badan Akreditasi Nasional Perguruan Tinggi termsuk program studi teknik kimia. Akamigas Balongan harus terus menjamin mutunya dalam memberikan pelayanan dan menciptakan lulusan yang unggul, untuk melihat sejauh mana sistem manajemen mutu perguruan tinggi terjamin. Akamigas Balongan pada program studi teknik kimia belum tersertifikasi ISO 9001:2015 dikarenakan didalam sistem manajemen ISO 9001:2015 terdapat banyak persyaratan atau klausul yang harus dipenuhi jika perguruan tinggi ingin mendapat pengakuan atau sertifikasi ISO 9001:2015. ISO 9001:2015 memiliki klausul yang didalamnya terdapat terdapat komponenkomponen persyaratan yang dibutuhkan untuk sertifikasi. Banyaknya komponen dalam klausul ISO 9001:2015 yang harus dipenuhi membuat fokus pelaksana sistem penjaminan mutu terpecah dan sulit menetukan prioritas pada pekerjaannya.

Berdasarkan latar belakang tersebut, peneliti ingin mengembangkan strategi dalam rencana persiapan implementasi sistem manajemen mutu berdasarkan persyaratan yang ada pada ISO 9001:2015 agar dapat mengetahui komponen apa saja yang menjadi kunci dalam mendukung kerberhasilan dalam persiapan rencana implementasi sistem manajemen mutu ISO 9001:2015 di Akamigas Baloangan pada program studi teknik kimia agar sistem penjamin mutu dapat fokus pada beberapa komponen untuk mencapai keberhasilan dalam melakukan

\section{METODE PENELITIAN}

Penelitian ini menggunakan metode deksriptif kualitatif, pengambilan sampel menggunakan metode purposive sampling dan untuk analisa data menggunakan metode Interpretative Structural Modeling (ISM).

\section{Interpretative Structural Modeling (ISM)}

Menurut penelitian [3]. Interpretative Structural Modeling (ISM) yaitu metodologi yang digunakan untuk mengidentifikasi dan meringkas hubungan yang saling berkaitan antara perihal khusus dari suatu masalah atau isu. Program terbagi dalam 9 elemen, yaitu:

1. Sektor masyarakat yang terpengaruh

2. Kebutuhan program

3. Kendala utama program

4. Kemungkinan perubahan dalam program

5. Tujuan program

6. Tolok ukur untuk menilai setiap tujuan program

7. Aktivitas yang dibutuhkan untuk merencanakan tindakan 
8. Ukuran aktivitas untuk mengevaluasi hasil yang sudah dicapai dari setiap aktivitas

9. Lembaga yang terlibat pada pelaksanaan program.

Menurut [4] metode ISM terdiri atas 3 tahap, berikut langkah-langkahnya:

1. Identifikasi Sistem

Meliputi:

1) Merumuskan tujuan, yaitu sesuatu yang menjadi fokus dari kajian.

2) Mengidentifikasi elemen dan sub elemen melalui studi pustaka, brainstorming dan survei pakar.

3) Menyusun hubungan kontekstual, didasarkan pada VAXO $(\mathrm{V}=$ Elemen i memengaruhi Elemen j, A $=$ Elemen $\mathrm{j}$ memengaruhi Elemen $\mathrm{i}$, $\mathrm{X}=$ kedua elemen saling memengaruhi antara $\mathrm{i}$ dan $\mathrm{j}, \mathrm{O}=$ kedua elemen $\mathrm{i}$ dan $\mathrm{j}$ tidak saling mempengaruhi). Hubungan kontekstual tersebut disusun dalam bentuk daftar pertanyaan dengan pola perbandingan berpasangan.

4) Menentukan responden pakar, kriteria pakar bisa dikategorikan menjadi:

a. Kepakaran atau keahlian dikarenakan keilmuan dalam jenjang akademik atau peneliti.

b. Kepakaran atau keahlian dikarenakan kedudukan yakni sebagai pengambil kebijakan.

c. Kepakaran atau keahlian dikarenakan kekhususan, seperti tokoh adat, tokoh agama, atau tokoh masyarakat dan lainnya.

2. Analisis (Run Software)

Meliputi:

1) Tabulasi data.

2) Input data.

3) Menyusun matriks SSIM (Structural Self-Interaction Matrix).

4) Menyusun matriks reachibility (RM) dalam bentuk matriks biner.

5) Matriks RM bersumber dari konversi matriks SSIM.

6) Dengan menggunakan, hukum perubahan bentuk hubungan konstekstual menjadi bentuk hubungan matematik, maka diperoleh matriks reachibility (RM).

7) Mengecek konsistensi matriks biner, dilakukan pengecekan dengan Kaidah transitivitas yang merupakan kelengkapan dari lingkaran sebab akibat.

8) Menyusun matriks reachibility final (RM Final).

9) Penentuan Driven Power dan Dependence. Nilai driven power diperoleh dengan menjumlahkan nilai elemen secara horizontal, sedangkan nilai dependence diperoleh dengan menjumlahkan nilai elemen secara vertikal.

10) Perumusan kedudukan dalam kuadran ISM. Kedudukan elemen/sub elemen didasarkan pada nilai Dependence dan nilai Driven Power. Menurut ${ }^{[3]}$ ada 4 (empat) kedudukan kuadran yang terdiri dari kuadran I (independent), kuadran II (linkage), kuadran III (dependent), dan kuadran IV (autonomous). Klasifikasi kuadran independent yaitu elemen yang mempunyai kekuatan pengaruh yang tinggi, dan ketergantungannya rendah terhadap program. Klasifikasi kuadran linkage adalah kuadran yang mempunyai hubungan antar peubah yang kurang stabil dan setiap tindakan pada perubah tersebut akan memberikan dampak terhadap sub elemen yang lainnya dan umpan balik pengaruhnya dapat memperbesar dampak, sehingga 
Suci Amaliah: Implementasi Sistem Manajemen Mutu ISO 9001: 2015 pada Program Studi Teknik Kimia di Akademi Minyak dan Gas Balongan Menggunakan Metode Interpretative Structural Modeling (ISM) Jurnal Migasian, e-issn: 2615-6695 / p-issn: 2580-5258

sub elemen ini harus dikaji secara hati-hati. Klasifikasi kuadran dependent yaitu sub elemen yang terikat. Klasifikasi kuadran autonomus adalah sub elemen yang tidak langsung terkait dengan sistem, dan mungkin mempunyai hubungan yang tidak banyak, tetapi dapat lebih kuat berpengaruh pada pencapaian tujuan.

11) Penyusunan level, didasarkan pada nilai level yang diperoleh dari matriks driven power dan dependence. Level kunci atau level pertama adalah elemen yang mempunyai nilai tertinggi dan seterusnya.

3. Interpretasi Output

Meliputi:

1) Interpretasi kedudukan setiap elemen dalam kuadran.

2) Interpretasi level.

Untuk penggunakan metode ISM bisa di lakukan dengan menggunakan software, tahap yang dilakukan dengan menggunakan software yang membantu dalam tahap analisis dan interpretasi output. Software yang digunakan bisa dengan software ISM Profesional 2.0 yang merupakan software ISM berbasis website, alamat jaringannya yaitu [4]

https://statistikawanku.shinyapps.io/ism_so ftware/.

Metode ISM menghasilkan 3 hal yaitu: elemen kunci, truktur hirarki elemen, dan pengelompokan elemen dalam 4 kuadran klasifikasi.

\section{HASIL DAN PEMBAHASAN}

Peneliti menggunakan softwere ISM Profesional 2.0 yang merupakan aplikasi berbasis website. Tahap dalam menggunakan metode ini yaitu:

1. Identifikasi Sistem
1) Tujuan sistem adalah analisa persiapan implementasi Sistem

2) Manajemen Mutu ISO 9001: 2015 pada program studi teknik kimia di Akademi Minyak dan Gas Balongan.

3) Elemen kajiannya yaitu elemen kebutuhan karena dalam mengimplementasikan SMM ISO 9001:2015 harus memenuhi persyaratan yang sudah berlaku, persyaratan tersebut dibutuhkan dalam penerapan SMM ISO 9001:2015 dan elemen kendala karena dalam mengiemplementasikan SMM ISO 9001:2015 akan menemukan kendala.

4) Elemen kebutuhan terdiri dari sub elemen pada tabel 1 berikut:

Tabel 1. Sub Elemen dari Elemen Kebuthuan

\begin{tabular}{cl}
\hline $\begin{array}{c}\text { Variabel } \\
\text { i }\end{array}$ & \multicolumn{1}{c}{ Sub Elemen } \\
\hline A1 & Konteks Organisasi \\
A2 & Kepemimpinan \\
A3 & Perencanaan \\
A4 & Pendukung \\
A5 & Operasi \\
A6 & Evaluasi Kinerja \\
A7 & Perbaikan \\
\hline
\end{tabular}

Elemen kendala terdiri dari sub elemen pada tabel 2 berikut: 
Tabel 2. Sub Elemen dari Elemen Kendala

\begin{tabular}{|c|c|}
\hline $\begin{array}{l}\text { Variabel } \\
\mathbf{j}\end{array}$ & Sub Elemen \\
\hline B1 & $\begin{array}{l}\text { Faktor eksternal yang dibutuhkan untuk sesuai dengan ISO } \\
\text { 9001:2015 belum terpenuhi }\end{array}$ \\
\hline B2 & Biro-brio yang kurang memahami standar operasioal prosedur \\
\hline B3 & $\begin{array}{l}\text { Kurangnya peran manajemen puncak untuk memastikan bahwa } \\
\text { sistem manajemem mutu telah mencapai hasil yang diinginkan }\end{array}$ \\
\hline B4 & $\begin{array}{l}\text { Manajemen institusi belum menentukan rencana perubahan } \\
\text { untuk sistem manajemen mutu }\end{array}$ \\
\hline B5 & Kurang tersedianya sumber daya yang dibutuhkan \\
\hline B6 & $\begin{array}{l}\text { Laboraturium praktikum untuk mahasiswa belum memenuhi } \\
\text { standar }\end{array}$ \\
\hline B7 & $\begin{array}{l}\text { Software yang digunakan pada masing-masing biro masih } \\
\text { terspisah }\end{array}$ \\
\hline B8 & $\begin{array}{l}\text { Software untuk menyimpan dan mengolah data belum } \\
\text { ditingkatkan sistem keamanannya }\end{array}$ \\
\hline B9 & Audit mutu internal belum di lakukan \\
\hline B10 & $\begin{array}{l}\text { Belum adanya informasi terdokumentasi terkait pelaksanaan } \\
\text { audit }\end{array}$ \\
\hline B11 & $\begin{array}{l}\text { Belum adanya dokumen dari hasil tinjauan dan tidak lanjut dari } \\
\text { masing-masing biro dan manajemen puncak }\end{array}$ \\
\hline
\end{tabular}

5) Menyusun daftar pertanyaan untuk mendapat hubungan kontekstual antar elemen.

6) Menentukan responden pakar, dalam penelitian ini peneliti menggunakan 4 (empat) orang pakar.

7) Tabulasi data, hasil dari penilaian dari responden pakar ditabulasi dalam microsoft excel dengan format .CSV (comma demilimted).
2. Analisis (Run Softwere)

Buka softwere ISM Profesional 2.0 dengan mengakses link https://statistikawanku.shinyapps.io/is m_software/, input data sesusai dengan data yang sudah didapatkan dan proses menggunakan softwere tersebut. Interpretasi Output

Hasil dari proses analisis menggunakan software tersebut meliputi:

a. Elemen Kebutuhan

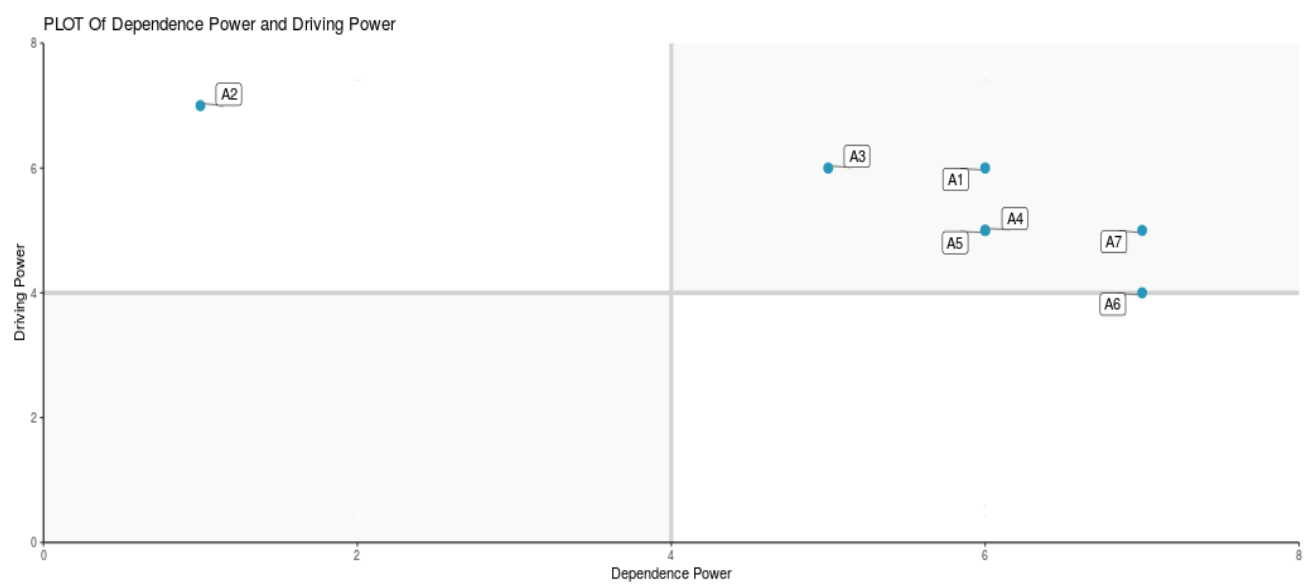

Gambar 1. Output Analisis Grafik Kuadran Elemen Kebutuhan 
Suci Amaliah: Implementasi Sistem Manajemen Mutu ISO 9001: 2015 pada Program Studi Teknik Kimia di Akademi Minyak dan Gas Balongan Menggunakan Metode Interpretative Structural Modeling (ISM) Jurnal Migasian, e-issn: 2615-6695 / p-issn: 2580-5258

Hasil analisis menunjukan elemen kebutuhan ada pada 2 (dua) kuadran pada Gambar 1 yaitu: sub elemen sub elemen A2 (Kepemimpinan) di kuadran I (Independent), selanjutnya sub elemen A1 (Konteks Organisasi), sub elemen A3 (Perencanaan), sub elemen A4
(Pendukung), sub elemen A5 (Operasi), sub elemen A6 (Evaluasi Kinerja), dan sub elemen A7 (Perbaikan) berada di kuadran II (Linkage).

Dari hasil grafik kuadran didapatkan grafik level pada Gambar 2 sebagai berkut:

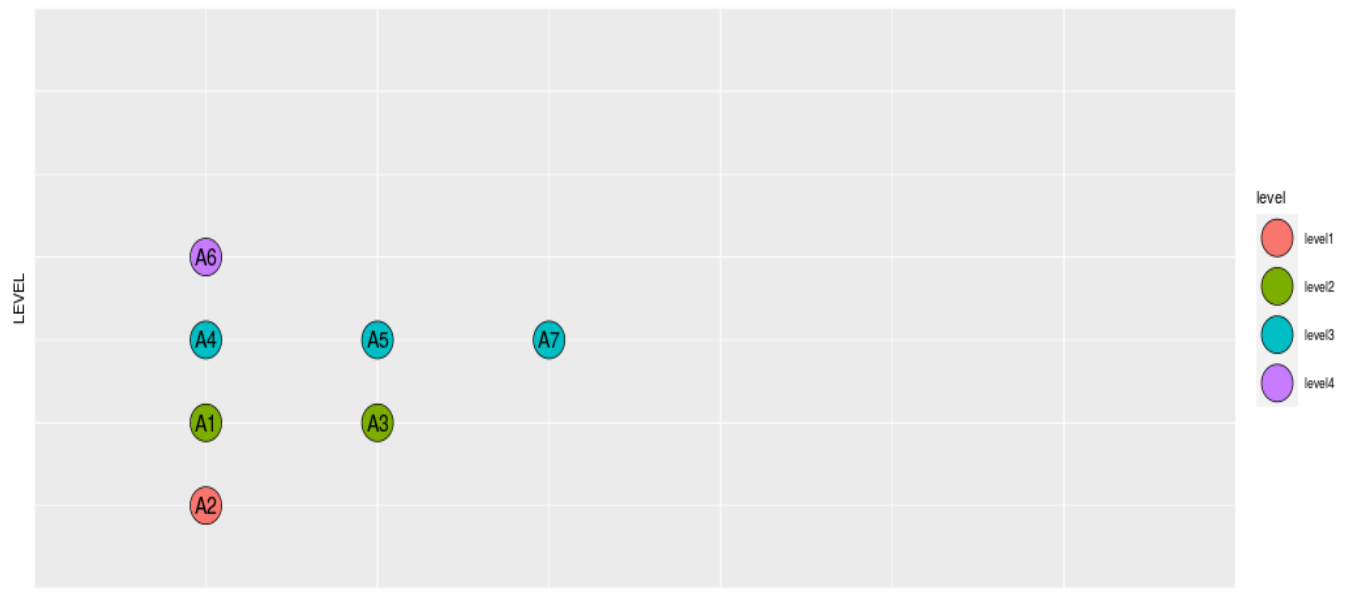

Gambar 2. Output Analisis Grafik Level Elemen Kebutuhan

Grafik level menunjukkan bahwa level 1 atau elemen kuncinya yaitu sub elemen A2 (Kepemimpinan), di level 2 yaitu sub elemen A1 (Konteks Organisasi) dan sub elemen A3 (Perencanaan), di level 3 yaitu sub elemen A4 (Pendukung), sub elemen A5 (Operasi) dan sub elemen A7 (Perbaikan), serta level 4 sub elemen A6 (Evaluasi Kinerja).

Kesimpulannya kunci persyaratan yang dibutuhkan dalam impelementasi SMM ISO 9001:2015 di Program Studi Teknik Kimia Akamigas Balongan yaitu A2 (Kluasul Kepemimpinan).

Menurut hasil olahan data peneliti dengan elemen kebutuhan didapatkan sub elemen kuncinya yaitu kepemimpinan, peran manjemen puncak di Akamigas Balongan pada prorgam studi teknik kimia sangat penting dalam mendukung keberhasilan dalam penerapan sistem manajemen mutu ISO 9001:2015. Jadi, untuk persiapan implementasi sistem manajemen mutu ISO 9001:2015 di
Akamigas Balongan pada program studi teknik kimia berdasarkan hasil pengolahan data (berdasarkan grafik kuadran dan grafik level) yang harus di perispakan terlebih dahulu untuk jangka pendeknya yaitu klausul kepemimpinan, untuk jangka menengan yaitu klausul konteks ogranisasi dan klausul perencanaan lalu dilanjutkan dengan klausul pendukung, klausul operasi dan perbaikan, seta untuk jangka panjangnya yaitu evaluasi kinerja.

Ini sesuai dengan [5] peran manajemen puncak atau pimpinan perguruan tinggi merupakan hal yang sangat penting dalam mendukung keberhasilan sistem manajemen mutu, di pergruan tinggi pada setiap prosesnya memerlukan konsistensi dan pelayanan yang tinggi, ini belum bisa terlaksana tanpa adanya komitmen pimpinan untuk menagrahkan sumber daya yang pada sistem manajemen mutu. Komptensi pimpinan perguruan tinggi juga hal yang penting karena pimpinan yang pernah 
terlibat dalam proses penyusunan standar mutu, menjadi pelaksana proses dalam proses mutu akan terasah, mempunyai pengalaman dan kepakaran yang cukup untuk memimpin, mengarahkan dan menjalankan sistem manajemen mutu pada seluruh divisi. Adanya komitmen dan kompetensi maka pimpinan mampu menularkan komitmen dan arahan yang jelas untuk memastikan seluruh prosesnya berjalan sesuai dengan standar mutu dan menggerakan semua komponen institusi untuk mencapai target yang sudah ditentukan [5].

b. Elemen Kendala

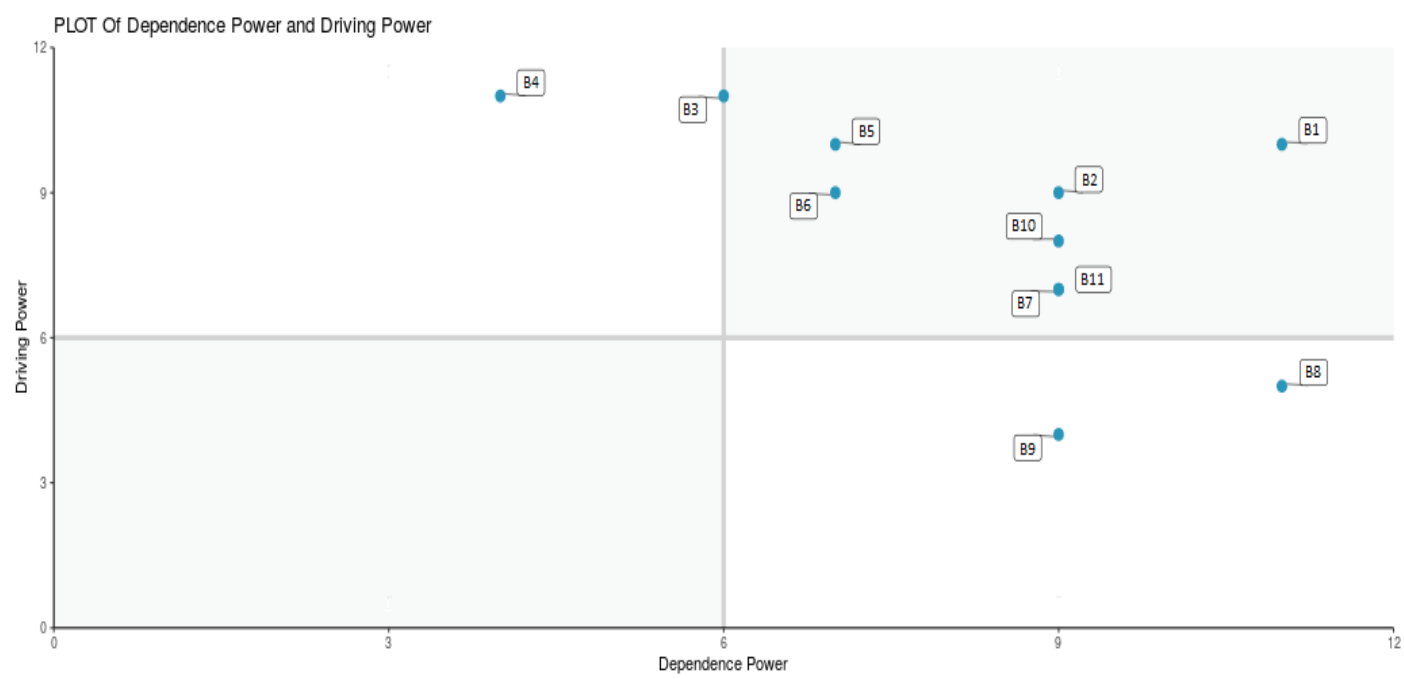

Gambar 3. Output Analisis Grafik Kuadran Elemen Kendala

Hasil analisis menunjukan elemen kendala ada pada 3 (tiga) kuadran pada Gambar 3 yaitu sub elemen B3 (Kurangnya peran manajemen puncak untuk memastikan bahwa sistem manajemem mutu telah mencapai hasil yang diinginkan) dan B4 (Manajemen institusi belum menentukan rencana perubahan untuk sistem manajemen mutu) pada kuadran I (Independent), selanjutnya B1 (Faktor eksternal yang dibutuhkan untuk sesuai dengan ISO 9001:2015 belum terpenuhi), B2 (Biro-brio yang kurang memahami standar operasioal prosedur), B3 (Kurangnya peran manajemen puncak untuk memastikan bahwa sistem manajemem mutu telah mencapai hasil yang diinginkan), B5 (Kurang tersedianya sumber daya yang dibutuhkan), B6 (Laboraturium praktikum untuk mahasiswa belum memenuhi standar), B7 (Software yang digunakan pada masing-masing biro masih terspisah), B10 (Belum adanya informasi terdokumentasi terkait pelaksanaan audit) dan B11 (Belum adanya dokumen dari hasil tinjauan dan tidak lanjut dari masing-masing biro dan manajemen puncak) berada pada kuadran II (linkage), selanjutnya B8 (Software untuk menyimpan dan mengolah data belum ditingkatkan sistem keamanannya) dan B9 (Audit mutu internal belum dilakukan) dan pada kuadran III (Dependent).

Dari hasil grafik kuadran didapatkan grafik level pada Gambar 4 sebagai berkut: 


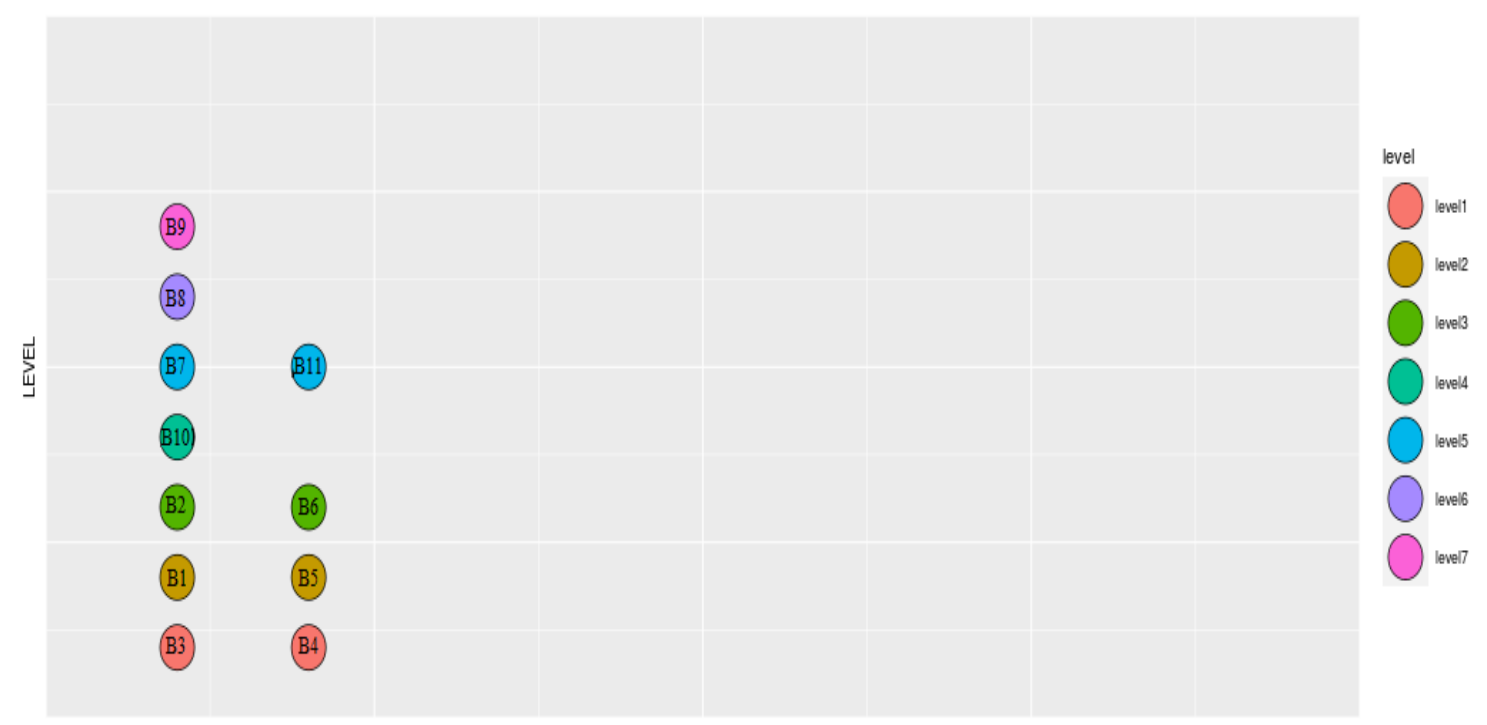

Gambar 4. Output Analisis Grafik Level Elemen Kendala

Grafik level menunjukan bahwa level 1 atau elemen kuncinya yaitu sub elemen B3 (Kurangnya peran manajemen puncak untuk memastikan bahwa sistem manajemem mutu telah mencapai hasil yang diinginkan) dan sub elemen B4 (Manajemen institusi belum menentukan rencana perubahan untuk sistem manajemen mutu), di level 2 yaitu sub elemen B1 (Faktor eksternal yang dibutuhkan untuk sesuai dengan ISO 9001:2015 belum terpenuhi) dan sub elemen B5 (Kurang tersedianya sumber daya yang dibutuhkan), di level 3 yaitu sub elemen B2 (Biro-brio yang kurang memahami standar operasioal prosedur) dan sub elemen B6 (Laboraturium praktikum untuk mahasiswa belum memenuhi standar), di level 4 yaitu sub elemen B10 (Belum adanya informasi terdokumentasi terkait pelaksanaan audit), di level 5 yaitu sub elemen B7 (Software yang digunakan pada masing-masing biro masih terspisah) dan sub elemen B11 (Belum adanya dokumen dari hasil tinjauan dan tidak lanjut dari masing-masing biro dan manajemen puncak), di level 6 yaitu sub elemen B8 (Software untuk menyimpan dan mengolah data belum ditingkatkan sistem keamanannya), serta di level 7 yaitu sub elemen B9 (Audit mutu internal belum di lakukan).

Kesimpulannya kunci kendala pada implementasi SMM ISO 9001:2015 di Program Studi Teknik Kimia Akamigas Balongan yaitu B3 (Kurangnya peran manajemen puncak untuk memastikan bahwa sistem manajemem mutu telah mencapai hasil yang diinginkan) dan B4 (Manajemen institusi belum menentukan rencana perubahan untuk sistem manajemen mutu). Jadi, untuk persiapan implementasi sistem manajemen mutu ISO 9001:2015 di Akamigas Balongan pada program studi teknik kimia berdasarkan hasil pengolahan data (berdasarkan grafik kuadran dan grafik level) kendala yang harus diatasi terlebih dahulu yaitu kurangnya peran manajemen puncak untuk memastikan bahwa sistem manajemem mutu telah mencapai hasil yang diinginkan dan manajemen institusi belum menentukan rencana perubahan untuk sistem manajemen mutu, kendala selanjutnya kendala pada faktor eksternal yang dibutuhkan untuk sesuai dengan ISO 9001:2015 belum terpenuhi dan kurang tersedianya sumber daya yang dibutuhkan, 
lalu mengatasi kendala pada biro-brio yang kurang memahami standar operasioal prosedur dan laboraturium praktikum untuk mahasiswa belum memenuhi standar), selanjutnya kendala belum adanya informasi terdokumentasi terkait pelaksanaan audit, lalu kendala software yang digunakan pada masing-masing biro masih terspisah dan belum adanya dokumen dari hasil tinjauan dan tidak lanjut dari masing-masing biro dan manajemen puncak, dan kendala pada software untuk menyimpan dan mengolah data belum ditingkatkan sistem keamanannya), serta kendala audit mutu internal belum di lakukan.

Menurut hasil olahan data peneliti dengan elemen kendala didapatkan sub elemen kuncinya sub elemen kurangnya peran manajemen puncak untuk memastikan bahwa sistem manajemem mutu telah mencapai hasil yang diinginkan dan sub elemen manajemen institusi belum menentukan rencana perubahan untuk sistem manajemen mutu, sesuai dengan elemen kebutuhannya yaitu sub elemen kepemimpinan. Ini relevan dengan hasil penelitian $^{[5]}$ salah satu faktor yang mendukung keberhasilan sistem manajemen mutu di pergurun tinggi yaitu komitmen dan kompetensi pimpinan.

Manajemen institusi harus menentukan rencana perubahan untuk sistem manajemen mutu, karena manajemen institusi menentukan kebutuhan perubahan sistem manajemen atau proses, perubahan ini direncanakan, dilaksanakan, dan kemudian diverifikasi untuk efektivitas perubahan akan membahas pada rapat tinjauan manajemen ${ }^{[6]}$. Perencanaan perubahan juga harus di pertimbangkan seperti kebutuhan dari sistem manajemen mutu, ketersediaan sumberdaya, alokasi tanggung jawab dan wewenang.

\section{KESIMPULAN}

Berdasarkan hasil analisis dengan menggunakan metode ISM menunjukan bahawa dalam elemen kebutuhan terdapat kunci persyaratan yang dibutuhkan dalam strategi rencana persiapan impelementasi SMM ISO 9001:2015 di Program Studi Teknik Kimia Akamigas Balongan yaitu sub elemen kepemimpinan dan dalam elemen kendala terdapat kunci kendala pada implementasi SMM ISO 9001:2015 di Program Studi Teknik Kimia Akamigas Balongan yaitu kurangnya peran manajemen puncak untuk memastikan bahwa sistem manajemem mutu telah mencapai hasil yang diinginkan dan manajemen institusi belum menentukan rencana perubahan untuk sistem manajemen mutu.

\section{DAFTAR PUSTAKA}

[1] E. N. Ma'sumah, Layaman, "Pengaruh Implementasi Sistem Manajemen Mutu ISO 9001:2015 Terhadap Kepuasan Peserta (Pelanggan) Dengan Mediasi Kualitas Layanan", Jurnal Bisnis dan Manajemen, vol. 9, no. 1, pp. 69 - 78, Mei 2018

[2] Y. Nurjanah, "Implementasi ISO 9001:2015 di Fakultas Teknik Universitas Diponegoro". Jurnal Pustaka Ilmiah, vol. 2, no. 2, pp. 231 239, Desember 2016

[3] M. D. D. Maharani, D. V. Sara, "Model Struktural Pengelolaan Tempat Penampungan Dan Pemotongan Secara Berkelanjutan Dalam Mendukung Ketahanan Pangan", Seminar Nasional FMIPA Universitas Terbuka, vol. 1, no. 1 , pp. $69-93,2018$

[4] M. Yusuf, Y. S. Setiawan, E. A. Supeni, "Decision Support System Di 
Suci Amaliah: Implementasi Sistem Manajemen Mutu ISO 9001: 2015 pada Program Studi Teknik Kimia di Akademi Minyak dan Gas Balongan Menggunakan Metode Interpretative Structural Modeling (ISM) Jurnal Migasian, e-issn: 2615-6695 / p-issn: 2580-5258

Era 4.0 Teori \& Aplikasi Tools Analysis", Bogor, IPB Press, 2020

[5] Y. K. Dewi, "Faktor Pendukung Keberhasilan Penerapan Sistem Penjaminan Mutu Di Perguruan Tinggi”, Business Management Journal, vol. 14, no. 1, pp. $37-48$, 2018

[6] E. Sundari, "Pengaruh Penerapan Manajemen Mutu ISO 9001:2015 Terhadap Manajemen Perpustakaan SMK-SMTI Banda Aceh", S. IIP. Skripsi. Universitas Islam Negeri ArRaniry, Banda Aceh, 2020 